\title{
Blame or Provoked Responsibility?
}

\author{
Jessica Inch \\ BJARN Editor
}

$\mathrm{H}$ ope you all had a great Christmas and New Year and that you have settled into 2007. This year holds great things for BARNA, with a number of study days both run and sponsored by us as well as our annual conference in Brighton. This year also sees the revision of the Association's constitution available soon, as well as BARNA's official Peri-operative Competency Framework. As always, I invite your comments regarding all aspects of this journal, so get in touch.

Picture the scene. An ambulance pulls up to a site of devastation. A lorry travelling at high speed has caused a large pile up during rush hour on the M25, leaving the driver and a number of others seriously hurt. The paramedics assess the scene and begin to treat the car owners first, not because they need priority care but because they are not to blame for this horrific situation. Can you imagine the outcry?

This sounds far fetched and inconceivable, but could this be the way that health care is headed? At the end of last year, the Government announced that overweight patients may soon be expected to sign a weight-loss contract to get slim before receiving a new joint on the NHS. This follows Tony Blair's aim of basing new health policy around the theme of 'rights and responsibilities', which is done by creating a range of 'contracts' between the service using citizen and the state. This came alongside a number of Primary Care Trusts earmarking patients scheduled for routine surgery and referring them to a smoking cessation clinic and given a target time to give up. So, is this prompting responsibility or denying a group of patients the surgery that they are entitled to when they need it the most?
So is this a government struggling to do its bit for health improvement, forcing individuals to take responsibility for their own actions and outcomes? Last year statistics showed that $20 \%$ of adults have a BMI greater than 30 with Britain coming third in an obesity league table after America and Malta. There is no doubt that we are not exactly pleased with the way our nation is expanding and this could be the ultimate in 'wanting the best for our patients'.

The case for loosing weight and cutting down/stopping smoking is well researched and accepted. There is no doubt that a patient will experience a quicker, less complicated recovery if weight is lost and/or smoking stopped, but why is it that currently in my experience, a known alcoholic can often skip the 'police check' and receive elective surgery. Personally, I think that it is important not to differentiate between these actions and other harmful activities after all alcoholism is now considered a medical condition, with the above still being termed an 'addiction' or 'habit'. Are they not all actions to which there are some degree of loss of control? After all smoking and alcohol are linked by the fact that some groups, such as the mentally ill, are prone to both. Smoking also needs to be considered an addiction. As for being overweight, this country is finding it increasingly easier to assign blame and vilify those who partake. As a country we have become less tolerant towards the smoking and overweight. When was the last time you picked up a paper or watched the news without an item on obesity or the effects of smoking? I believe that if we start to police one behaviour we must, to some degree police all. 
However, does any health care professional have the right to refuse an elective procedure to those who are inhibiting their own outcome? We often hear 'I pay my taxes just like everyone else'. Is it practical to withhold elective hip replacement surgery from an overweight individual, if by definition are not fit enough to partake in the prescribed exercise that is needed for required weight loss?
If we are to police these 'habits', where do we eventually stop? I think it must sit prominently in our minds that the healthcare professional who denies much needed treatment specifically on the grounds of being a smoker, or being overweight can themselves be violating their human rights on the bases of discriminating against a disability. 